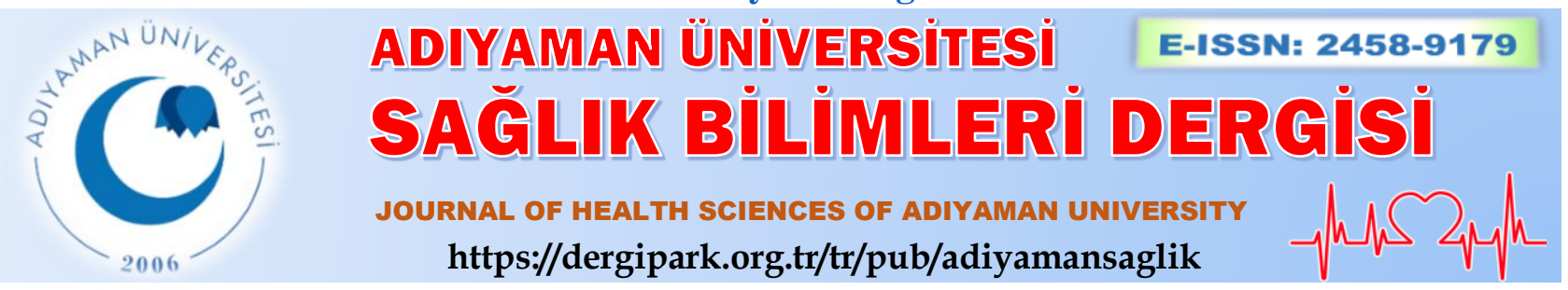

\title{
Türkiye'deki İBBS-1 bölgelerinin sağlık hizmeti sunum etkinliğinin veri zarflama analizi kullanılarak ölçülmesi
}

\section{Measuring of healthcare service delivery efficiency of NUTS-1 territories in Turkey using data envelopment analysis}

\author{
Aydın ÖZDEMIR 1 @(D) \\ ${ }^{1}$ Adıyaman Üniversitesi, Besni Meslek Yüksekokulu, Yönetim ve Organizasyon Bölümü, 02300, Adıyaman-Türkiye
}

Atıf gösterme/Cite this article as: Özdemir A. Türkiye'deki ibbs-1 bölgelerinin sağlık hizmeti sunum etkinliğinin veri zarflama analizi kullanılarak ölçülmesi. ADYÜ Sağllk Bilimleri Derg. 2020;6(2):231-242. doi:10.30569.adiyamansaglik. 708826

$\ddot{\mathbf{O} z}$

Amaç: Türkiye'deki İstatistiki Bölge Birimleri Sınıflandırması-1 (IBBBS-1) bölgelerinin sağlık hizmeti sunum etkinliklerini ölçmek.

Gereç ve Yöntem: Bu çalışmada üç girdi ve üç çıktı değişkeni kullanılarak, on iki İstatistiki Bölge Birimleri Sınıflandırmas1-1 (İBBS-1) bölgesi üzerinde Veri Zarflama Analizi yürütülmüştür.

Bulgular: Analiz sonuçları tüm modeller bakımından Batı Karadeniz, Doğu Marmara, Güneydoğu Anadolu ve Kuzeydoğu Anadolu'nun etkin olduğunu ve Akdeniz, Doğu Karadeniz, İstanbul, Orta Anadolu ve Ortadoğu Anadolu'nun etkin olmadığını göstermektedir. Bunun yanı sıra, Batı Anadolu, Batı Marmara ve Ege'nin sadece Banker, Charnes, Cooper (BCC) modelleri bakımından etkin olduğu belirlenmiştir.

Sonuç: Batı Karadeniz, Doğu Marmara, Güneydoğu Anadolu ve Kuzeydoğu Anadolu etkin olarak Akdeniz, Doğu Karadeniz, İstanbul, Orta Anadolu ve Ortadoğu Anadolu ise etkinsiz olarak saptanmıştır. Bu sonuçların yeni girdi ve çıktı değişkenleri eklenerek ve Network ve Two-Stage Veri Zarflama Analizi gibi yeni nesil Veri Zarflama Analizi teknikleri kullanılarak bulanık ortamda doğrulanması önerilmektedir.

Anahtar Kelimeler: Etkinlik; Veri Zarflama Analizi; Sağlık Hizmeti Sunumu.

\begin{abstract}
Aim: Measuring the of healthcare service delivery of Nomenclature of Territorial Units for Statistics-1 (NUTS-1) territories in Turkey.

Materials and Methods: Data Envelopment Analysis was conducted on the twelve Nomenclature of Territorial Units for Statistics-1 (NUTS-1) territories using three input variables and three output variables.

Results: The results of the analysis demonstrate that Western Blacksea, Eastern Marmara, Southeastern Anatolia and Northeastern Anatolia are efficient and, Mediterranean, Eastern Blacksea, Istanbul, Central Anatolia and Mideastern Anatolia are inefficient in terms of all models. Besides, it is determined that Western Anatolia, Western Marmara and Aegean are efficient only in terms of Banker, Charnes, Cooper (BCC) models.

Conclusion: It was determined as Western Blacksea, Eastern Marmara, Southeastern Anatolia and Northeastern Anatolia are efficient and, Mediterranean, Eastern Blacksea, Istanbul, Central Anatolia and Mideastern Anatolia are inefficient. It is suggested that confirm in the fuzzy environment these results adding new input and output variables and, using new generation Data Envelopment Analysis techniques such as Network and Two-Stage Data Envelopment Analysis.

Keywords: Efficiency; Data Envelopment Analysis; Healthcare Delivery.
\end{abstract}

Yazışma Adresi/Address for Correspondence: Aydın ÖZDEMİR, Adıyaman Üniversitesi, Besni Meslek Yüksekokulu, Yönetim ve Organizasyon Bölümü, 02300, Adıyaman-Türkiye, E-mail: aydinozdemir17@gmail.com

Geliş Tarihi/Received:24.03.2020 Kabul Tarihi/Accepted:15.06.2020 Yayım Tarihi/Published online:30.08.2020 


\section{Giriş}

Sağlık hizmeti kalitesinin aşağıda açıklanan altı boyutu bulunmaktadır. ${ }^{1}$

- Güvenlik: Sağlık tesisleri hastalar için kendi evleri kadar güvenli olmalıdır.

- Etkililik: Sağlık hizmeti sunumunda bilim ve kanıt standart olarak uygulanmalidir.

- Etkinlik: Sağlık hizmeti mali açıdan etkin olmalı ve sistemden israf kaldırılmalıdır.

- Tam Vaktinde: Hastalar sağlık hizmeti alırken bekleme veya gecikme yaşamamalıdır.

- Hasta Merkezli: Sağlık hizmeti sistemi hastanın etrafında dönmeli, hastanın tercihlerine saygı duymalı ve hastayı kontrol altına almalıdır.

- Eşitlikçi: Eşit olmayan muamele dünün bir gerçeği olmalı ve eşitsizliklerin kökü kurutulmalıdır.

Sağlık hizmetinin kalitesi ve sağlık hizmetine erişim fonksiyonel sağlık hizmeti için iki kritik sonuç niteliğindedir. ${ }^{2}$ İnsan merkezli ve entegre sağlık hizmeti ulusal ve küresel olarak sağlıklı bir ortama ulaşmak için kritik bir öneme sahiptir. ${ }^{3}$ Çünkü hastalar sağllk sisteminde hayati bir paydaş olarak yer almaktadır. $^{4}$

Birçok ülkede daha etkin, daha sistematik ve en optimal sağlık hizmeti sunabilmek için sağlik sistemleri yeniden organize edilmektedir. ${ }^{5}$ Türkiye de bu bağlamda 2003 yılında "Sağlıkta Dönüşüm Programı" ile tüm sağlık sisteminde köklü değişiklik ve iyileştirmelere imza atmıştır. Sağlikta Dönüşüm Program1; Kavramsallaştırma, Yasalaşma, Kontrollü Yerel Uygulamalar ve Türkiye Geneline Yaygınlaştırma olmak üzere temel olarak dört aşamayı içermektedir. ${ }^{6}$

Fabrika İçinde Fabrika (Plant within a plant-PWP) yaklaşımında bir tesisin hem organizasyonel hem de fiziksel olarak çeşitli parçalara bölündüğünü ve her bir tesisisin kendine özgü üretim/işlemler görevine odaklandığını dile getirilmiştir. ${ }^{7}$ Temelini Adam Smith'in öne sürdüğü iş bölümü yaklaşımından alan bu yaklaşım çeşitli sektörlerde faaliyet gösteren gerek özel gerekse de kamu menşeili birçok organizasyonu etkilemiştir. Çünkü Adam Smith iş bölümü yapmanın organizasyonların kendine özgü üretim/işlemlerini de hesaba katması yönünden dolayı işletmeleri/organizasyonları daha iyi anlamaya yardımcı olabileceğini belirtmiştir. ${ }^{8}$ İş bölümü yaklaşımı organizasyonlarda farklı yöntemlerle hayata geçirilebilir. Örneğin, Avrupa Komisyonu Avrupa Birliği ülkelerinin üç farklı NUTS (Nomenclature of territorial units for statistics) ekonomik bölgesine (NUTS-1, NUTS-2 ve NUTS-3) ayrılmasını öngören bir coğrafi sınıflandırma sistemi kullanmaktadır.9 Avrupa Birliği'ne uyum çerçevesinde Türkiye de bu sinıflandırmaya benzer bir İstatistiki Bölge Birimleri Sınıflandırması (İBBS) yapmış olup söz konusu siniflandirma İBBS-1, 12 bölgeden; İBBS-2, 26 bölgeden ve İBBS-3, 81 ilden oluşmaktadır. ${ }^{10}$ Wikner vd.'nin ise Ayrıştırma Düşüncesi (Decoupling Thinking) olarak adlandırdığ 1 ve genellikle üretim/işlemler yönetimi ile tedarik zinciri yönetimi yazınında kendine yer bulan bu yaklaşımın hizmet işlemlerinde özellikle de sağlik hizmeti işlemlerinde uygulanabileceğini ifade etmiştir. ${ }^{11}$

Sosyal, ekonomik ve teknolojik değişimler ülkeleri sağlı sistemlerini dinamik tutmaya zorlar. $^{12}$ Ancak kırsal bölgelerde yaşayan bireylerin sınırlı mali imkanları, ulaşım zorluğu, fiziksel engeller vb. nedenlerden ötürü sağlık hizmetinden yararlanma oranları kentlerde yaşayan bireylere göre nispeten daha düşük olmaktadır. ${ }^{13}$ Temel amacı bölgeler arasındaki sağlık, sosyal, ekonomik ve teknolojik alanlardaki farklılıkları minimize etmek olan bölgesel kalkınma politikası, katılımcılık ve sürdürülebilirliği temel ilke edinen ve beşeri kaynaklarının niceliksel ve niteliksel iyileştirilmesi suretiyle bölge refahını yükseltmeyi hedefler ${ }^{14}$. Her bir bölge kendine has özelliklere ve sorunlara sahip olduğundan bölgesel gelişme spesifik koşullara adapte olmayı gerektiren bir süreçtir. $^{15}$

Türkiye bölgesel kalkınma ekseninde İstatistiki Bölge Birimleri Sinıflandırması (İBS) yapmıştır. ${ }^{16}$ söz konusu İstatistiki Bölge Birimleri Sınıflandırması tüm ülkelerde olduğu gibi Türkiye'de de birçok disiplinin 
ilgisini çekmiş ve araştırmalarında kullandığı bir sınıflandırma olmuştur. Örneğin, coğrafya, ekonomi, sağlık vb. İstatistiki Bölge Birimleri Sinıflandırması kullanılarak yapılan çalışmalardır. ${ }^{17}{ }^{18}{ }_{-}{ }^{19} \_20$

İstatistiki Bölge Birimleri (İBBS) sınıflandırması bölgesel kalkınma, ekonomi, vb. birçok alanda olduğu gibi sağlık hizmetleri alanında da bölgeler arası benzerlik ve farklılıkları belirlemek amaciyla kullanılan bir sınıflandırmadır. Bu çalışmanın amacı, İstatistiki Bölge Birimleri Sinıflandırması içerisinde yer alan 12 adet birinci düzey (İBBS-1) bölgelerindeki sağlı hizmeti sunumlarının etkinliği Veri Zarflama Analizi (VZA) kullanarak analiz etmektir.

\section{Gereç ve Yöntem}

\section{Araştırmanın tipi}

Araştırma ikincil verilerle etkinlik değerlendirme üzerine kurgulanan nicel (kantitatif) bir çalışmadır. $\mathrm{Bu}$ amaçla araştırmada Veri Zarflama Analizi kullanılmıştır.

Veri Zarflama Analizi (VZA); ortak girdi ve çıktılara sahip Karar Verme Birimi (KVB) olarak adlandırılan bir girişim dizisinin göreli etkinliklerini karşılaştırır. $^{21}$ Veri Zarflama temeli Farrell'in 1957 yılında tek girdi ve tek çıktı ile yaptığı analize dayanmakla birlikte Charnes vd.'nin 1978 yılındaki çalışması bu yöntemin başlangıç noktası olarak kabul edilir. ${ }^{22}{ }^{23}$ Veri Zarflama Analizi, işletmeler, okullar, hastaneler vb. bir Karar Verme Biriminin etkinliğini ölçen parametrik olmayan bir yöntemdir. ${ }^{24}$ Veri Zarflama Analizinde kullanılan temel etkinlik ölçümü toplam çıktıların toplam girdilere oranına dayanır. ${ }^{25}$ Veri Zarflama Analizi, aşağıdaki modelleri bir içeren kavramlar ve metodolojiler setidir. ${ }^{26}$

- CCR Model; genel etkinliğin tarafsız değerlendirilmesini sağlar, kaynakları tanımlar, kaynakların miktarını tahmin eder.

- BCC Model; teknik etkinlik ve ölçek etkinliğini ayırır.

- Çarpımsal Modeller (Multiplicative Models)

- Toplanır Modeller (Additive Models)
CCR Modelinde sanal girdi ve sanal çıktılar ağırlıklarıyla birlikte üretilir. BCC Modelinde ise KVB'lerin dışbükey bir zarfı çevrelenen üretim sınırları vardır. ${ }^{27}$

Belirli bir miktardaki çıktıyı daha az girdi ile elde etmeye odaklanan yaklaşıma Girdi Yönelimli VZA; belirli bir miktardaki girdiyle daha fazla çıktı elde etmeye odaklanan yaklaşıma ise Çıktı Yönelimli VZA denir. ${ }^{25}$

CCR-Girdi Yönelimli (1), CCR-Çıktı Yönelimli (2), BCC-Girdi Yönelimli(3) ve BCC Çıktı Yönelimli (4) Veri Zarflama Analizi modellerine ait formüller aşağıdaki gibidir. ${ }^{28}$

$$
\boldsymbol{E f f}=\min _{\boldsymbol{u}_{\boldsymbol{r}} \boldsymbol{v}_{\boldsymbol{i}}} \sum_{\mathrm{i}} \boldsymbol{V}_{\mathrm{I}} \boldsymbol{X}_{\mathrm{I} \mathrm{J}_{0}}
$$

s.t.

$$
\sum_{r} u_{r} y_{r j}-\sum_{i} v_{i} x_{i j} \leq 0 ; \forall j
$$

$$
\begin{aligned}
& \sum_{r} u_{r} y_{r j_{0}}=1 \\
& u_{r}, v_{i} \geq 0 ; \forall r, \forall i .
\end{aligned}
$$

$$
E f f=\max _{u_{r} v_{i}} \sum_{r} u_{r} y_{r j_{0}}
$$

s.t.

$$
\begin{aligned}
& \sum_{r} u_{r} y_{r j}-\sum_{i} v_{i} x_{i j} \leq 0 ; \forall j \\
& \sum_{i} v_{i} x_{i j_{0}}=1 \\
& u_{r}, v_{i} \geq 0 ; \forall r, \forall i .
\end{aligned}
$$

$$
\min _{\lambda, \emptyset, S_{i}^{-}, S_{r}^{+}} \emptyset
$$

s.t. 


$$
\begin{aligned}
& \sum_{j} \lambda_{j} x_{i j}+S_{i}^{-}=\emptyset_{x_{i j_{0}}} \forall i \\
& \sum_{j} \lambda_{j} y_{r j}-S_{r}^{+}=y_{r j_{0}} \forall r \\
& \sum_{j} \lambda_{j}=1 \\
& s_{i}^{-}, s_{i}^{+} \geq 0 \quad \forall i, \forall r \\
& \lambda_{j} \geq 0 \quad \forall j .
\end{aligned}
$$

\section{$\max _{\lambda, \emptyset, S_{i}^{-}, S_{r}^{+}} \boldsymbol{\theta}$}

s.t.

$$
\begin{aligned}
& \sum_{j} \lambda_{j} x_{i j}+S_{i}^{-}=x_{i j_{0}} \forall i \\
& \sum_{j} \lambda_{j} y_{r j}-S_{r}^{+}=\theta y_{r j_{0}} \forall r \\
& \sum_{j} \lambda_{j}=1 \\
& s_{i}^{-}, s_{i}^{+} \geq 0 \quad \forall i, \forall r \\
& \lambda_{j} \geq 0 \quad \forall j .
\end{aligned}
$$

Performans değerlendirme, sürekli iyileştirme için etkin bir araç olup VZA performans değerlendirmesi için birçok alanda kullanılan etkin bir analizdir. ${ }^{29} \mathrm{Bu}$ alanların içerisinde konaklama, yiyecekiçecek perakende, bankacilık, sigortacılık, finansal hizmetler, medya, ulaştırma, bilgi teknolojileri, sağlık vb. yer almaktadır. ${ }^{28}$

VZA'nın en sık kullanıldığı alanlardan olan sağlık alanı ile Türkiye örnekleminde yapılan birçok çalışma bulunmaktadır. Örneğin, Çınaroğlu 2019 yılında Türkiye'deki 81 ilde yer alan 688 kamu hastanesinin etkinliğini analiz etmiş olup söz konusu illeri etkinlik skorlarına göre kümeleme analizine tabi tutmuştur. ${ }^{12}$ Yeşilaydın 2017 yılında Türkiye'de sağlık alanında VZA kullanılarak yapılan çalışmaları sistematik bir incelemeye tabi tutmuştur. ${ }^{30}$ Ertugay vd. 2019 yılında girdi değişkenleri olarak; doktor sayısı, hemşire sayısı ve diğer sağlık çalışanı sayısını çıktı değişkenleri olarak; işlem sayısı, yatak doluluk oranı ve bir sene içerisinde her bin kişiye isabet eden ölüm sayısını alarak Türkiye'de 81 ilin sağlık etkinliğini analiz etmiştir. $^{31}$ Sülkü 2012 y1lında girdi değişkenleri olarak; yatak sayısı, uzman sayısı ve pratisyen sayısını çıktı değişkenleri olarak; ayakta tedavi sayıs1, yatan hasta sayıs1, toplam ameliyat sayısinı alarak 81 il örnekleminde 2001-2006 yıllarını kıyaslayarak Sağlık Dönüşüm Programının etkisini analiz etmiştir. ${ }^{32}$ Keskin 2018 yılında girdi değişkenleri olarak; hekim sayısı, yardımcı hizmet sınıfı personel sayısı, teknik ve yönetsel personel sayıs1 ve aktif kullanımda olan hasta yatağı sayısını, çıktı değişkenleri olarak; yatan hasta gün sayısı, ayaktan hasta ziyaretlerinin sayısı ve ağırlıklı ameliyat sayısını alarak kamu hastaneleri özelinde Sağlıkta Dönüşüm Programının etkinliğini analiz etmiştir. ${ }^{33}$

\section{Araştırmanın evreni ve örneklemi}

$\mathrm{Bu}$ çalışma, Karar Verme Birimi (KVB) olarak İstatistiki Bölge Birimleri Sınıflaması (İBBS) içerisinde yer alan 12 adet İBBS-1 düzey bölgesinin tümünü kapsamaktadır. Karar Verme Birimi (KVB); benzer girdileri kullanarak benzer çıktıları üretmeye çalışan birimlerdir. ${ }^{27}$ Çalışmaya tüm İBBS-1 düzey bölgelerinin dahil edilmesi Karar Verme Birimlerinin (KVB) homojenliğgi ile ilgili üç kriteri tatmin etmektedir. $\mathrm{Bu}$ kriterler; KVB'lerin aynı amaçlarla benzer görevler icra etmesi, bütün KVB'lerinin benzer pazar koşulları altında faaliyet göstermesi ve KVB'lerin aynı girdi ve aynı çıktıları kullanmasıdır. ${ }^{34}$

Analizde kullanılan veriler KVB'ler ve bunlara ait veriler 2018 Sağlık İstatistikleri Yıllığından elde edilmiştir. ${ }^{35}$ Söz konusu KVB'ler Tablo 1'de yer almaktadır.

\section{Veri toplama araçları}

Etkinlik ölçümleri, kritik bir biçimde esnek girdi-çıktı bileşimlerinin nasıl oluşturulduğuna bağlıdır. ${ }^{24}$ Araştırmada kullanılan girdi ve çıktılar veriler 2018 Sağlık İstatistikleri Yıllığından elde edilmiş olup Tablo 2'de gösterilmiştir. ${ }^{35}$ 
Tablo 1. Çalışmada Kullanılan Karar Verme Birimleri (KVB)

\begin{tabular}{|c|c|c|c|}
\hline Sayı & $\begin{array}{c}\text { İBBS-1 } \\
(\text { Düzey-1) } \\
\end{array}$ & $\begin{array}{c}\text { İBBS-2 } \\
\text { (Düzey-2) }\end{array}$ & $\begin{array}{c}\text { İBBS-3 } \\
\text { (Düzey-3) } \\
\end{array}$ \\
\hline \multirow{3}{*}{1} & \multirow{3}{*}{ Akdeniz (A) } & Antalya Alt Bölgesi & $\begin{array}{l}\text { Antalya } \\
\text { Isparta } \\
\text { Burdur }\end{array}$ \\
\hline & & Adana Alt Bölgesi & $\begin{array}{l}\text { Adana } \\
\text { Mersin } \\
\end{array}$ \\
\hline & & Hatay Alt Bölgesi & $\begin{array}{c}\text { Hatay } \\
\text { Kahramanmaraş } \\
\text { Osmaniye }\end{array}$ \\
\hline \multirow[b]{2}{*}{2} & \multirow[b]{2}{*}{ Batı Anadolu (BA) } & Ankara Alt Bölgesi & Ankara \\
\hline & & Konya Alt Bölgesi & $\begin{array}{c}\text { Konya } \\
\text { Karaman }\end{array}$ \\
\hline \multirow{3}{*}{3} & \multirow{3}{*}{ Batı Karadeniz (BK) } & Zonguldak Alt Bölgesi & $\begin{array}{c}\text { Zonguldak } \\
\text { Karabük } \\
\text { Bartın }\end{array}$ \\
\hline & & Kastamonu Alt Bölgesi & $\begin{array}{c}\text { Kastamonu } \\
\text { Çankırı } \\
\text { Sinop }\end{array}$ \\
\hline & & Samsun Alt Bölgesi & $\begin{array}{c}\text { Samsun } \\
\text { Tokat } \\
\text { Çorum } \\
\text { Amasya } \\
\end{array}$ \\
\hline \multirow[t]{2}{*}{4} & \multirow[t]{2}{*}{ Batı Marmara (BM) } & $\begin{array}{l}\text { Tekirdağ Alt } \\
\text { Bölgesi }\end{array}$ & $\begin{array}{l}\text { Tekirdağ } \\
\text { Edirne } \\
\text { Kurklareli }\end{array}$ \\
\hline & & Balıkesir Alt Bölgesi & $\begin{array}{c}\text { Balıkesir } \\
\text { Çanakkale }\end{array}$ \\
\hline 5 & Doğu Karadeniz (DK) & Trabzon Alt Bölgesi & $\begin{array}{c}\text { Trabzon } \\
\text { Ordu } \\
\text { Giresun } \\
\text { Rize } \\
\text { Artvin } \\
\text { Gümüşhane }\end{array}$ \\
\hline \multirow[b]{2}{*}{6} & \multirow[b]{2}{*}{ Doğu Marmara (DM) } & Bursa Alt Bölgesi & $\begin{array}{c}\text { Bursa } \\
\text { Eskişehir } \\
\text { Bilecik } \\
\end{array}$ \\
\hline & & Kocaeli Alt Bölgesi & $\begin{array}{l}\text { Kocaeli } \\
\text { Sakarya } \\
\text { Düzce } \\
\text { Bolu } \\
\text { Yalova } \\
\end{array}$ \\
\hline \multirow{3}{*}{7} & \multirow{3}{*}{ Ege $(E)$} & İzmir Alt Bölgesi & İzmir \\
\hline & & Aydın Alt Bölgesi & $\begin{array}{l}\text { Aydın } \\
\text { Denizli } \\
\text { Muğla } \\
\end{array}$ \\
\hline & & Manisa Alt Bölgesi & $\begin{array}{c}\text { Manisa } \\
\text { Afyonkarahisar } \\
\text { Kütahya } \\
\text { Uşak } \\
\end{array}$ \\
\hline \multirow{3}{*}{8} & \multirow{3}{*}{ Güneydoğu Anadolu (GDA) } & Gaziantep Alt Bölgesi & $\begin{array}{c}\text { Gaziantep } \\
\text { Adıyaman } \\
\text { Kilis } \\
\end{array}$ \\
\hline & & Şanlıurfa Alt Bölgesi & $\begin{array}{c}\text { Şanlıurfa } \\
\text { Diyarbakır }\end{array}$ \\
\hline & & Mardin Alt Bölgesi & $\begin{array}{c}\text { Mardin } \\
\text { Batman } \\
\text { Şırnak } \\
\text { Siirt } \\
\end{array}$ \\
\hline 9 & İstanbul (I) & İstanbul Alt Bölgesi & İstanbul \\
\hline
\end{tabular}




\begin{tabular}{|c|c|c|c|}
\hline \multirow[b]{2}{*}{10} & \multirow[b]{2}{*}{ Kuzeydoğu Anadolu (KDA) } & Erzurum Alt Bölgesi & $\begin{array}{c}\text { Erzurum } \\
\text { Erzincan } \\
\text { Bayburt }\end{array}$ \\
\hline & & Ağrı Alt Bölgesi & $\begin{array}{c}\text { A ̆ğr1 } \\
\text { Kars } \\
\text { Iğdır } \\
\text { Ardahan }\end{array}$ \\
\hline \multirow{2}{*}{11} & \multirow{2}{*}{ Ortadoğu Anadolu (ODA) } & Malatya Alt Bölgesi & $\begin{array}{c}\text { Malatya } \\
\text { Elazı̆ } \\
\text { Bingöl } \\
\text { Tunceli } \\
\end{array}$ \\
\hline & & Van Alt Bölgesi & $\begin{array}{c}\text { Van } \\
\text { Muş } \\
\text { Bitlis } \\
\text { Hakkari } \\
\end{array}$ \\
\hline \multirow[t]{2}{*}{12} & \multirow[t]{2}{*}{ Orta Anadolu (OA) } & Kırıkkale Alt Bölgesi & $\begin{array}{l}\text { Kırıkkale } \\
\text { Aksaray } \\
\text { Niğde } \\
\text { Nevşehir } \\
\text { Kırşehir }\end{array}$ \\
\hline & & Kayseri Alt Bölgesi & $\begin{array}{c}\text { Kayseri } \\
\text { Sivas } \\
\text { Yozgat }\end{array}$ \\
\hline
\end{tabular}

Tablo 2. Girdi ve Çıktı Değişkenleri

\begin{tabular}{|c|c|}
\hline Girdiler & Çıktılar \\
\hline $\begin{array}{l}100.000 \text { Kişiye Düşen Toplam Hekim Sayısı } \\
\text { (i1) }\end{array}$ & $\begin{array}{l}\text { Kişi Başı Hekime Müracaat Sayısı } \\
\text { (O1) }\end{array}$ \\
\hline $\begin{array}{c}100.000 \text { Kişiye Düşen Hemşire ve Ebe Sayıs1 } \\
\text { (i2) }\end{array}$ & $\begin{array}{l}\text { Kişi Başı Diş Hekimine Müracaat Sayısı } \\
\text { (O2) }\end{array}$ \\
\hline $\begin{array}{c}10.000 \text { Kişiye Düşen Hastane Yatağ1 Sayısı } \\
\text { (i3) }\end{array}$ & $\begin{array}{c}\text { Hastanelerde Yatak Doluluk Oranı } \\
(\mathbf{O B})\end{array}$ \\
\hline
\end{tabular}

VZA'da kullanılacak KVB sayısının girdi ve çıtıların sayısından daha fazla olması gerektiği hatta mümkünse KVB sayısının girdi ve çıktı sayılarının toplamının 2 veya 3 kat1 olması gerektiğini belirtilmektedir. ${ }^{25}$ Araştırma kapsamında 12 (oniki) KVB'nin göreli etkinlikleri 3 (üç) girdi değişkeni ve 3 (üç) çıktı değişkeni kullanılarak ölçüldüğünden bu koşul sağlanmıştır.

Çalışmada kullanılan girdi ve çıktı değişkenleri literatürde yer alan ilgili çalışmalar ile büyük ölçüde benzerlikler göstermektedir. ${ }^{33,32,12,30,31}$ Söz konusu girdi ve çıktı değişkenlerine ait minimum, maksimum ve ortalama değerler Tablo 3'te yer almaktadır

Tablo 3'e göre; 100.000 Kişiye Düşen Toplam Hekim Sayıs1 (i1) ortalamas1 $(177,4)$, 100.000 Kişiye Düşen Hemşire ve Ebe Sayısı (i2) ortalaması $(311,8), 10.000$ Kişiye Düşen Hastane Yatağı Sayısı (i3) ortalaması $(29,07)$, Kişi Başı Hekime Müracaat Sayısı (O1) ortalaması $(9,458)$, Kişi Başı Diş Hekimine Müracaat Sayıs1 $(\mathrm{O} 2)$ ortalaması $(0,6750)$ ve Hastanelerde Yatak Doluluk Oranı (O3) ortalaması $(66,67)$ olarak tespit edilmiştir.

Tablo 3. Girdi ve Çıktı Değişkenlerine Ait Minimum, Maksimum ve Ortalama Değerler

\begin{tabular}{rlll|rlll}
\hline Girdiler & Min & Max & Ort. & Çıktılar & Min & Max & Ort. \\
\hline (i1) & 129,0 & 267,0 & 177,4 & (O1) & 7,900 & 10,400 & 9,458 \\
\hline (i2) & 248,0 & 368,0 & 311,8 & (O2) & 0,5500 & 0,8100 & 0,6750 \\
\hline (i3) & 23,20 & 33,20 & 29,07 & (O3) & 58,00 & 72,20 & 66,67 \\
\hline
\end{tabular}

\section{Verilerin analizi}

Analiz kapsamında ele alınan İBBS-1 bölgelerini için hem girdi yönelimli hem de çıktı yönelimli CCR ve BCC modelleri tercih edilmiştir. Bir başka ifadeyle; KVB'leri için hem sabit getiri varsayımı altında çalışan CCR modelinin girdileri minimize etmeye odaklanan girdi yönelimli versiyonu ve çıktıları maksimize etmeye çalışan çıktı 
yönelimli versiyonu hem de değişken getiri varsayımı altında çalışan BCC modelinin girdileri minimize etmeye odaklanan girdi yönelimli versiyonu ve çıktıları maksimize etmeye çalışan çıktı yönelimli versiyonu kullanılarak Toplam Teknik Etkinlik ve Saf Teknik Etkinlik değerleri hesaplanmıştır. CCR Modelinde Toplam Teknik Etkinlik değerlendirilirken BCC Modelinde Saf Teknik Etkinlik değerlendirilir. ${ }^{36}$

Ayrıca hem girdi yönelimli CCR ve BCC Modelleri için hem de çıktı yönelimli CCR ve BCC Modelleri için Ölçek Etkinliği değerleri hesaplanmıştır. Girdi yönelimli veya Çıktı Yönelimli modellerinin her biri için Toplam Teknik Etkinlik (CCR) değerinin Saf Teknik Etkinlik (BCC) değerine bölünmesi ile elde edilir ve Ölçek Etkinliği değeri 1.00'dan büyük olması mümkün değildir. ${ }^{27}$
Modellerin çözümü açık kaynak kodlu istatistiksel hesaplama ve grafik yazılımı olan "R" üzerinde "rDEA" kütüphanesi ile yapılmıştır. ${ }^{37,38}$

\section{Araştırmanın etik boyutu}

Araştırma Helsinki Bildirgesi'nde bahsedilen "insan gönüller" üzerinde yapılmayıp T.C. Sağlık Bakanlığı’nın kamuoyuna açık bir biçimde yayınladığı ikincil veriler kullanılarak yürütüldüğünden Etik Kurul iznine ihtiyaç duyulmamaktadır.

\section{Bulgular}

Analiz sonucunda elde edilen Toplam Etkinlik ve Saf Teknik Etkinlik Değerleri Tablo 4'te verilmiştir.

Tablo 4. İBBS-1 Bölgelerinin Toplam Teknik Etkinlik ve Saf Teknik Etkinlik Değerleri

\begin{tabular}{|c|c|c|c|c|c|c|}
\hline \multirow{2}{*}{ İBBS-1 } & \multicolumn{2}{|c|}{ Toplam Teknik Etkinlik } & \multicolumn{2}{|c|}{ Saf Teknik Etkinlik } & \multirow{2}{*}{$\begin{array}{c}\text { Ölçek } \\
\text { Etkinliği } \\
\text { (Girdi } \\
\text { Yönelimli) }\end{array}$} & \multirow{2}{*}{$\begin{array}{c}\text { Ölçek } \\
\text { Etkinliği } \\
\text { (Çıktı } \\
\text { Yönelimli) }\end{array}$} \\
\hline & $\begin{array}{c}\text { CCR } \\
\text { (Girdi } \\
\text { Yönelimli) }\end{array}$ & $\begin{array}{c}\text { CCR } \\
\text { (Çıktı } \\
\text { Yönelimli) }\end{array}$ & $\begin{array}{c}\text { BCC } \\
\text { (Girdi } \\
\text { Yönelimli) }\end{array}$ & $\begin{array}{c}\text { BCC } \\
\text { (Çıktı } \\
\text { Yönelimli) }\end{array}$ & & \\
\hline $\mathrm{A}$ & 0.9580783 & 0.9580783 & 0.9956407 & 0.9976569 & 0,962273137 & 0,960328446 \\
\hline BA & 0.9492477 & 0.9492477 & 1,0000000 & 1,0000000 & 0,9492477 & 0,9492477 \\
\hline BK & 1,0000000 & 1,0000000 & 1,0000000 & 1,0000000 & 1,0000000 & 1,0000000 \\
\hline $\mathrm{BM}$ & 0.9415157 & 0.9415157 & 1,0000000 & 1,0000000 & 0,9415157 & 0,9415157 \\
\hline DK & 0.8807313 & 0.8807313 & 0.9301584 & 0.9791329 & 0,946861631 & 0,899501283 \\
\hline DM & 1,0000000 & 1,0000000 & 1,0000000 & 1,0000000 & 1,0000000 & 1,0000000 \\
\hline$E$ & 0.9672523 & 0.9672523 & 1,0000000 & 1,0000000 & 0,9672523 & 0,9672523 \\
\hline GDA & 1,0000000 & 1,0000000 & 1,0000000 & 1,0000000 & 1,0000000 & 1,0000000 \\
\hline $\mathrm{I}$ & 0.9719208 & 0.9719208 & 0.9915123 & 0.9981992 & 0,98024079 & 0,973674192 \\
\hline KDA & 1,0000000 & 1,0000000 & 1,0000000 & 1,0000000 & 1,0000000 & 1,0000000 \\
\hline $\mathrm{OA}$ & 0.9759896 & 0.9759896 & 0.9873130 & 0.9903849 & 0,988531094 & 0,985464944 \\
\hline ODA & 0.8900391 & 0.8900391 & 0.9285977 & 0.8920392 & 0,958476529 & 0,997757834 \\
\hline
\end{tabular}

Tablo 4'teki sonuçlar incelediğinde, CCR Modelleri açısından hem girdi yönelimli hem de çıktı yönelimli modellere göre, Batı Karadeniz (BK), Doğu Marmara (DM), Güneydoğu Anadolu (GDA) ve Kuzeydoğu Anadolu (KDA) İBBS-1 bölgelerinin etkinlik skorlarının 1 olduğu ve göreli etkinliğe ulaştıkları görülmektedir.

BCC Modelleri açısından hem girdi yönelimli hem de çıktı yönelimli modellere göre, Batı Anadolu (BA), Batı Karadeniz (BK), Batı Marmara (BM), Doğu Marmara (DM), Güneydoğu Anadolu (GDA) ve Kuzeydoğu Anadolu (KDA) İBBS-1 bölgelerinin etkinlik skorlarının 1 olduğu ve göreli etkinliğe ulaştıkları görülmektedir.
Ölçek Etkinliği skorları açısından hem girdi yönelimli hem de çıktı yönelimli modellere göre, Batı Karadeniz (BK), Doğu Marmara (DM), Güneydoğu Anadolu (GDA) ve Kuzeydoğu Anadolu (KDA) İBBS-1 bölgelerinin etkinlik skorlarının 1 olduğu ve göreli etkinliğe ulaştıkları görülmektedir.

Veri Zarflama Analizinde etkin olmayan KVB'lerin etkin duruma gelebilmeleri için referans kümeleri oluşturulmaktadır. ${ }^{39}$ Referans kümesi veya etkinlik hedefleri, etkinlik değerlendirmesine tabi tutulan KVB'yi etkin hale getirmek için girdilerin nasıl azaltılacağını veya çıktıların nasıl arttırılacağını gösterir. ${ }^{29}$ Referans kümesi kavramı bazen analize tabi tutulan tüm 
KVB'ler için kullanılıp etkin KVB'lerin kümesine ise referans alt kümesi denilir. ${ }^{40}$

Referans kümesinde etkin olmayan KVB'lere karşılık gelen ve pozitif ağırlığa (Lambda $\lambda$ ) sahip olan etkin KVB'lere etkin akranlar (efficient peers) denir ve etkin olmayan KVB'lerin etkin KVB'lere benzemesi için girdilerini ne kadar azaltmaları gerektiği veya çıktıları ne kadar arttırmaları gerektiği bu ağırlık yardımıyla hesaplanır. ${ }^{41}$

KVB'lerin girdiler üzerindeki kontrol gücü göz önüne alınarak tercih edilen Girdi Yönelimli BCC Modeline göre etkin olmayan KVB'ler için referans alınan KVB'ler ve ağırlıkları (Lambda $\lambda$ ) Tablo 5'te verilmiştir.

Tablo 5'e göre etkin olan KVB'ler (koyu olarak yazılan); Batı Anadolu (BA), Batı Karadeniz (BK), Batı Marmara (BM), Doğu Marmara (DM), Ege (E), Güneydoğu Anadolu (GDA) ve Kuzeydoğu Anadolu (KDA)'dur. Etkin olmayan KVB'ler ise (italik olarak yazılan); Akdeniz (A), Doğu Karadeniz (DK), İstanbul (İ), Orta Anadolu (OA) ve Ortadoğu Anadolu (ODA)'dur.

Etkin olmayan KVB'ler için referans kümeleri oluşturulmuştur. Buna göre;

- Akdeniz (A) için referans kümesi; Batı Marmara (BM), Doğu Marmara (DM) ve Ege'den

- Doğu Karadeniz (DK) için referans kümesi; Batı Karadeniz (BK), Bat1 Marmara (BM), Doğu Marmara (DM) ve Güneydoğu Anadolu (GDA)'dan

- İstanbul (İ) için referans kümesi; Doğu Marmara (DM) ve Güneydoğu Anadolu (GDA)'dan

- Orta Anadolu (OA) için referans kümesi; Batı Karadeniz (BK), Doğu Marmara (DM) ve Kuzeydoğu Anadolu (KDA)'dan

- Ortadoğu Anadolu (ODA) için referans kümesi; Güneydoğu Anadolu (GDA) ve Kuzeydoğu Anadolu (KDA)'dan,

oluşmaktadır. Referans kümlerinde en çok yer alan KVB Doğu Marmara (DM)'dır.

Tablo 6'da etkin olmayan KVB'ler için potansiyel iyileştirme oranları (girdi azaltılması veya çıktı arttırılması) verilmiştir.
Tablo 6 incelendiğinde;

- "100.000 Kişiye Düşen Toplam Hekim Sayıs1 (i1)" açısından en fazla iyileştirmeye ihtiyaç duyan KVB'nin Doğu Karadeniz (DK) $(11,94)$ ve Ortadoğu Anadolu (ODA) $(10,21)$ olduğu,

- "100.000 Kişiye Düşen Hemşire ve Ebe Sayısı (i2)" açısından en fazla iyileştirmeye ihtiyaç duyan KVB'nin Doğu Karadeniz (DK) $(59,11)$ ve Ortadoğu Anadolu (ODA) $(59,05)$ olduğu,

- "10.000 Kişiye Düşen Hastane Yatağ1 Sayısı (i3)" açısından en fazla iyileştirmeye ihtiyaç duyan KVB'nin Ortadoğu Anadolu (ODA) $(5,72)$ olduğu,

- "Kişi Başı Hekime Müracaat Sayısı (O1)" açısından en fazla iyileştirmeye ihtiyaç duyan KVB'nin Doğu Karadeniz (DK) $(1,03)$ ve Ortadoğu Anadolu (ODA) $(0,645)$ olduğu ancak Akdeniz (A) ve Orta Anadolu (OA)'nun bu çıktı değişkeninde iyileştirmeye ihtiyacının olmadığı,

- "Kişi Başı Diş Hekimine Müracaat Sayısı (O2)" açısından en fazla iyileştirmeye ihtiyaç duyan KVB'nin Akdeniz (A) $(0,14)$, Doğu Karadeniz (DK) $(0,08)$ ve İstanbul (İ) $(0,08)$ olduğu ancak Ortadoğu Anadolu (ODA) ve Orta Anadolu (OA)'nun bu çıktı değişkeninde iyileştirmeye ihtiyacının olmadığı,

- "Hastanelerde Yatak Doluluk Oranı (O3)" açısından en fazla iyileştirmeye ihtiyaç duyan KVB'nin Ortadoğu Anadolu (ODA) (8,35), Orta Anadolu (OA) (7,80) ve Doğu Karadeniz (DK) $(6,90)$ olduğu ancak İstanbul (I)'un bu çıtı değişkeninde iyileştirmeye ihtiyacının olmadığı, görülmektedir.

\section{Tartışma}

Sağlıkta Dönüşüm Programı ile vatandaşların ihtiyaç duyduğu sağlık hizmetlerine hızlı, hakkaniyetli, kaliteli ve sürdürülebilir bir biçimde ulaşması öngörülmüştür. ${ }^{6} \mathrm{Bu}$ bağlamda sağlık hizmeti veren kurum/kuruluşların performanslarının değerlendirilmesi söz konusu programın başarısı ve sürdürülebilirliği açısında hayati bir önem taşımaktadır. 
Tablo 5. Etkin Olmayan İBBS-1 Bölgelerinin Referans Kümeleri ve Referans Ağırlıkları

\begin{tabular}{|c|c|c|c|c|c|c|c|c|c|c|c|c|c|}
\hline İBBS & Etkinlik & $\mathrm{A}$ & $\mathrm{BA}$ & BK & $\mathrm{BM}$ & DK & $\mathrm{DM}$ & $E$ & GDA & $\mathrm{I}$ & KDA & ODA & $\mathrm{OA}$ \\
\hline$A$ & 0,9956407 & 0 & 0 & 0,0000000 & $(0,2826737)$ & 0 & $(0,54346525)$ & $(0,173861)$ & 0,0000000 & 0 & 0,0000000 & 0 & 0 \\
\hline $\mathbf{B A}$ & 1,0000000 & $\mathbf{0}$ & 1 & 0,0000000 & 0,0000000 & $\mathbf{0}$ & 0,00000000 & 0,000000 & 0,0000000 & $\mathbf{0}$ & 0,0000000 & $\mathbf{0}$ & $\mathbf{0}$ \\
\hline BK & 1,0000000 & 0 & 0 & 1,0000000 & 0,0000000 & 0 & 0,00000000 & 0,000000 & 0,0000000 & 0 & 0,0000000 & 0 & 0 \\
\hline BM & 1,0000000 & 0 & 0 & 0,0000000 & 1,0000000 & 0 & 0,00000000 & 0,000000 & 0,0000000 & 0 & 0,0000000 & 0 & 0 \\
\hline$D K$ & 0,9301584 & 0 & 0 & $(0,1799732)$ & $(0,5428189)$ & 0 & $(0,09634255)$ & 0,000000 & $(0,1808653)$ & 0 & 0,0000000 & 0 & 0 \\
\hline DM & 1,0000000 & 0 & 0 & 0,0000000 & 0,0000000 & 0 & 1,00000000 & 0,000000 & 0,0000000 & 0 & 0,0000000 & 0 & 0 \\
\hline $\mathbf{E}$ & 1,0000000 & 0 & $\mathbf{0}$ & 0,0000000 & 0,0000000 & 0 & 0,00000000 & 1,000000 & 0,0000000 & $\mathbf{0}$ & 0,0000000 & 0 & 0 \\
\hline GDA & 1,0000000 & 0 & $\mathbf{0}$ & 0,0000000 & 0,0000000 & 0 & 0,00000000 & 0,000000 & 1,0000000 & 0 & 0,0000000 & 0 & 0 \\
\hline$\dot{I}$ & 0,9915123 & 0 & 0 & 0,0000000 & 0,0000000 & 0 & $(0,45833333)$ & 0,000000 & $(0,5416667)$ & 0 & 0,0000000 & 0 & 0 \\
\hline KDA & 1,0000000 & $\mathbf{0}$ & $\mathbf{0}$ & 0,0000000 & 0,0000000 & $\mathbf{0}$ & 0,00000000 & 0,000000 & 0,0000000 & $\mathbf{0}$ & 1,0000000 & $\mathbf{0}$ & $\mathbf{0}$ \\
\hline$O A$ & 0,9873130 & 0 & 0 & $(0,3419689)$ & 0,0000000 & 0 & $(0,28497409)$ & 0,000000 & 0,0000000 & 0 & $(0,3730570)$ & 0 & 0 \\
\hline$O D A$ & 0,9285977 & 0 & 0 & 0,0000000 & 0,0000000 & 0 & 0,00000000 & 0,000000 & $(0,8421053)$ & 0 & $(0,1578947)$ & 0 & 0 \\
\hline
\end{tabular}

Tablo 6. Etkin Olmayan KVB’ler İçin Potansiyel İyileștirme Oranları

\begin{tabular}{|c|c|c|c|c|c|c|}
\hline \multirow{2}{*}{ İyileştirme Oranları } & \multicolumn{3}{|c|}{ Girdiler } & \multicolumn{3}{|c|}{ Çıktılar } \\
\hline & İ1 & $\dot{\mathbf{I}} 2$ & $\dot{\mathbf{I} 3}$ & 01 & O2 & $\mathbf{O 3}$ \\
\hline $\mathbf{A}$ & $-0,76$ & $-1,33$ & $-1,62$ & 0,00 & 0,14 & 0,55 \\
\hline DK & $-11,94$ & $-59,11$ & $-0,67$ & 1,03 & 0,08 & 6,90 \\
\hline$\dot{\mathbf{I}}$ & $-71,67$ & $-2,29$ & $-1,85$ & 0,10 & 0,08 & 0,00 \\
\hline $\mathbf{O A}$ & $-9,02$ & $-4,07$ & $-1,89$ & 0,00 & 0,00 & 7,80 \\
\hline ODA & $-10,21$ & $-59,05$ & $-5,72$ & 0,64 & 0,00 & 8,35 \\
\hline
\end{tabular}

Performans değerlendirmesi sırasında Karar Verme Birimi (KVB) olarak iller, ilçeler hatta hastaneler alınabileceği gibi birbirine benzer özellikler gösteren bölgeler de KVB olarak alınabilir. Ulaşım olanaklarının artması ve küreselleşmenin getirdiği imkanlar göz önüne alındığında bireylerin sadece yaşadığı il/ilçedeki sağlık kuruluşlarından değil bunun yanı sıra yakın il/ilçelerdeki sağlı kuruluşlarından da sağlık hizmeti talebinde bulunması beklenir ve rasyonel bir durumdur. Çalışma bu durum göz önüne alınarak İBBS-1 bölgeleri özelinde gerçekleştirilmiştir.

Araştırma kapsamında “100.000 Kişiye Düşen Toplam Hekim Sayısı”, "100.000 Kişiye Düşen Hemşire ve Ebe Sayısı” ve "10.000 Kişiye Düşen Hastane Yatağı Sayısı" "olmak üzere üç adet girdi ile "Kişi Başı Hekime Müracaat Sayısı", "Kişi Başı Diş Hekime Müracaat
Sayısı" ve "Hastanelerde Yatak Doluluk Oranı" olmak üzere üç adet çıktı kullanılmıştır.

Araştırmada girdi olarak kullanılan hekim sayısı, hemşire ve ebe sayısı ile hastane yatağı sayısı değişkenleri sağlık hizmetinin verilebilmesi için gerekli olan en temel bileşenlerdir. Bununla birlikte çıktı olarak kullanılan hekime müracaat sayısı, diş hekimine müracaat sayısı ve hastanelerdeki doluluk oranı değişkenleri girdi değişkenlerinin sonucu olarak ortaya çıkmaktadır.

Çalışmada, Veri Zarflama Analizinin Girdi Yönelimli CCR, Çıktı Yönelimli CCR, Girdi Yönelimli BCC ve Çıktı Yönelimli BCC olmak üzere dört modelinin kullanılmıştır. Ayrıca hem girdi hem de çıktı yönelimli modeller için BCC Modeliyle elde edilen etkinlik skorunun CCR Modeliyle elde edilen etkinlik skoruna bölünmesiyle 
Ölçek Etkinliği skorları hesaplanmıştır. Bunun yanı sıra etkin olmayan KVB'ler için referans kümelerinin oluşturulması ve potansiyel iyileştirme oranlarının hesaplanması için KVB'lerin girdiler üzerindeki kontrol gücü göz önüne alınarak Girdi Yönelimli BCC Modeli tercih edilmiştir.

Etkinlik skorları genel olarak değerlendirildiğinde, tercih edilen tüm modellerde; Batı Karadeniz (BK), Doğu Marmara (DM), Güneydoğu Anadolu (GDA) ve Kuzeydoğu Anadolu (KDA) KVB'lerinin etkin olduğu belirlenmiștir. Bununla birlikte tercih edilen tüm modellerde; Akdeniz (A), Doğu Karadeniz (DK), İstanbul (İ), Orta Anadolu (OA) ve Ortadoğu Anadolu (ODA) KVB'lerinin etkin olmadikları tespit edilmiştir. Batı Anadolu (BA), Batı Marmara (BM) ve Ege (E) KVB'lerinin ise sadece BCC Modellerinde etkin olduğu belirlenmiştir.

Elde edilen sonuçlar Keskin'in 2018 yılında yaptığı çalışmasında bulduğu Güneydoğu Anadolu'nun en etkin olması ve İstanbul'un en az etkin olması bulgularıyla birebir uyuşmakla beraber Akdeniz (A) ve Orta Anadolu (OA)'nun etkinlik siralamasinda üst siralarda olması bulgularıyla uyuşmamaktadır $\mathrm{Bu}$ durumun söz konusu çalışmanın 2009-2014 periyodunu kapsamasına rağmen tarafımızca yapılan çalışmanın 2018 yılı verileriyle yürütülmüş olmasından kaynaklandığı düşünülmektedir. ${ }^{33}$

Ertugay vd. tarafindan 2019 yilında yapılan çalışmada Balıkesir, Bilecik, Bursa, Çankırı, Gaziantep, İstanbul, Samsun, Bayburt, Bartın Ardahan ve Yalova etkin iller olarak bulunmuştur. Tarafımızca İBBS-1 bölgelerinde icra edilen çalışma ile kıyaslandığında söz konusu çalışmada etkin olarak bulana illerin çoğunluğu çalışmamızda etkin olarak bulunan bölgelere girmektedir. İstanbul (I) özelinde ortaya çıkan farklılığın nedeninin Ertugay vd'nin çıktı değişkenleri arasında tanımlamış olduğu ölüm oranı değişkeni olduğu değerlendirilmektedir. ${ }^{31}$

Sülkü tarafindan 2012 yılında 2001 ve 2006 yılları arasındaki verileri kullanılarak yapılan çalışma neticesinde; Adıyaman, Ağrı, Bingöl, Bitlis, Gümüşhane, Hakkari, Kars,
Mardin, Muş, Siirt, Tunceli, Van, Bayburt, Batman, Şırnak, Ardahan ve Iğdır illerini sosyo-ekonomik olarak dezavantajlı iller arasında saymıştır. Ancak tarafımızca 2018 yılı verileri kullanılarak yapılan analiz neticesinde bu illerin önemli bir kısmı etkin olan düzey-1 bölgeleri içerisinde yer almaktadır. $^{32} \mathrm{Bu}$ durum Sağlikta Dönüşüm Programı'nın başarısı olarak değerlendirilmektedir.

Çalışmamızda yapılan analizde İstanbul'un hiçbir modelde etkin çıkmaması ve Ankara'nın da içinde yer aldığı Batı Anadolu (BA) düzey-1 bölgesinin sadece $\mathrm{BCC}$ modellerinde etkin çıkması sonucu, Çınaroğlu tarafindan 2019 yilında yapılan ve veri zarflama analizi ile kümelenme analizini entegre ettiği çalışmasında, Ankara ve İstanbul gibi metropoliten şehirlerdeki kamu hastanelerinde ortalama teknik etkinlik skorlarının düşük olduğunu bulgusuyla örtüşmektedir. ${ }^{12}$

\section{Araştırmanın kısıtlılıkları}

Araştırmada Türkiye'deki İstatistiki Bölge Birimleri Sinıflandırmas1-1 (IBBS-1) bölgelerinin etkinliği üç girdi ve üç çıktı değişkeni kullanılarak ölçülmesi araştırmanın kısıtı olarak değerlendirilmektedir.

\section{Sonuç}

Tüm VZA modellerinde, Batı Karadeniz (BK), Doğu Marmara (DM), Güneydoğu Anadolu (GDA) ve Kuzeydoğu Anadolu (KDA) KVB'lerinin etkin olduğu belirlenmiştir. Bununla birlikte tercih edilen tüm modellerde; Akdeniz (A), Doğu Karadeniz (DK), İstanbul (I), Orta Anadolu (OA) ve Ortadoğu Anadolu (ODA) KVB'lerinin etkin olmadıkları tespit edilmiştir.

$\mathrm{Bu}$ çalışma üç adet girdi ve üç adet çıktı değişkeni ile yürütülmüştür. Ancak girdi ve çıktıların sağlık hizmeti üretimi sırasında değişken bir hal alması, birbirinin yerine geçmesi veya girdi/çıktıların neden/sonuçlarının çeşitli evrelerde kademeli olarak ortaya çıkabilme ihtimalleri göz önüne alınarak sonraki araştırmacıların Network Veri Zarflama Analizi ve Two-Stage Veri Zarflama Analizi (İki Aşamalı Veri Zarflama 
Analizi) yaklaşımlarını kullanarak bulanık ortamda (fuzzy environment) analizleri yürütmeleri önerilmektedir.

\section{Araştırmanın Etik Boyutu}

Araştırma Helsinki Bildirgesi'nde bahsedilen "insan gönüller" üzerinde yapılmayıp T.C. Sağlı Bakanlığı'nın kamuoyuna açık bir biçimde yayınladığ 1 ikincil veriler kullanılarak yürütüldüğünden Etik Kurul iznine ihtiyaç duyulmamaktadır.

\section{Yazar Katkıları}

Araştırmanın tüm aşamaları yazar tarafindan yürütülmüştür.

\section{Çıkar Çatışması Beyanı}

Yazarın herhangi bir çıkara dayalı ilişkisi yoktur.

\section{Araştırma Desteği}

Çalışmayı maddi olarak destekleyen kişi/kuruluş yoktur.

\section{Kaynaklar}

1. Joshi MS, Berwick D. Healthcare Quality and the Patient. In: Ramsom ER, Joshi MS, Nash DB, Ransom SB, eds. Healthcare Quality Book: Vision, Strategy, and Tools. 3.Edt. Health Administration Press/AUPHA Press; 2008.

2. Washko MM, Fennell ML. The Epicenter of Effectiveness and Efficiency in Health Care Delivery: The Evolving U.S. Health Workforce. Health Serv Res. 2017;52:353-359. doi:10.1111/1475-6773.12662

3. WHO. Health systems service delivery. Published 2020. $\begin{array}{llll}\text { Accessed } & \text { March } & 4020 .\end{array}$ https://www.who.int/healthsystems/topics/delivery/en/

4. Wass V. The impact of change in healthcare delivery on medical education. Educ Prim Care. 2007;18(5):551-557. doi:10.1080/14739879.2007.11493587

5. Rossen CB, Buus N, Stenager E, Stenager E. Patient assessment within the context of healthcare delivery packages: A comparative analysis. Int J Nurs Stud. 2016;53:248-259. doi:10.1016/j.ijnurstu.2015.08.002

6. T.C. Sağlık Bakanlığı. Sağlıkta Dönüşüm Programı.; 2003.

7. Skinner W. The Focused Factory. Harv Bus Rev. 1974;52(3):113-121

8. Smith A. An Inquiry into the Nature and Causes of the Wealth of Nations. Strahan \& Cadeli; 1776.

9. Eurostat. Glossary:Nomenclature of territorial units for statistics (NUTS). Published 2020. Accessed February 26, 2020. https://ec.europa.eu/eurostat/

10. TÜİK. İBBS. Published 2005. Accessed February 26, 2020. https://biruni.tuik.gov.tr/DIESS/SiniflamaSurumDetayAction.d o? surumId=164\&turId=7\&turAdi $=5$. Coğrafi Sinıflamalar

11. Wikner J, Yang B, Yang Y, Williams SJ. Decoupling thinking in service operations: a case in healthcare delivery system design. Prod Plan Control. 2017;28(5):387-397. doi:10.1080/09537287.2017.1298869

12. Cinaroglu S. Integrated k-means clustering with data envelopment analysis of public hospital efficiency. Health Care Manag Sci. Published online 2019. doi:10.1007/s10729-01909491-3

13. Rush KL, Howlett L, Munro A, Burton L. Videoconference compared to telephone in healthcare delivery: A systematic review. Int $J$ Med Inform. 2018;118(February):44-53. doi:10.1016/j.ijmedinf.2018.07.007

14. Sevinç H. Bölgesel Kalkınma Sorunsalı: Türkiye'de Uygulanan
Bölgesel Kalkınma Politikaları. Girişimcilik ve Kalkınma Derg. 2011;3(2):35-54.

15. Šabić D, Vujadinović S. Regional development and regional policy. Zb Rad - Geogr Fak Univ u Beogradu. 2017;(651a):463-477. doi:10.5937/zrgfub1765463v

16. 2002/4720 Sayıl İstatistiki Bölge Birimleri Sinıflandırmasının Tanımlanmasina İlişkin Bakanlar Kurulu Karart.; 2002.

17. Taş B. AB Uyum Sürecinde Türkiye İçin Yeni Bir Bölge Kavramı: İstatistiki Bölge Birimleri Sinıflandırması (IBBS). Afyon Kocatepe Üniversitesi Sos Bilim Derg. 2006; VIII(2):185197.

18. Şengül Ü, Eslemian S, Eren M. Türkiye'de İstatistiki Bölge Birimleri Sınıflamasına Göre Düzey 2 Bölgelerinin Ekonomik Etkinliklerinin DEA Yöntemi ile Belirlenmesi ve Tobit Model Uygulamas1. Yönetim Bilim Derg. 2013;11(21):75-99.

19. Saraç S, Kesikoğlu F. Ar-Ge Harcamalarinin Büyüme Üzerindeki Etkïsi: İBBS Düzey 1 Bölgelerinin Karşılaştırmalı Analizi. Int J Manag Econ Bus. 2017;13(ICMEB17):617-627. doi:10.17130/ijmeb.2017icmeb1735474

20. Türkkan A. Sürdürülebilir Kalkınma Hedeflerindeki Ölümlülük Göstergelerine Göre Türkiyede Bölgesel Eşitsizlikler. Sağllk Yönetimi Derg. 2019;3(2):16-22.

21. Tone K. Radial DEA Models. In: Tone K, ed. Advances in DEA Theory and Applications With Extentions to Forecasting Models. Wiley \& Sons Ltd; 2017.

22. Farrell MJ. The Measurement of Productive Efficiency. J R Stat Soc Ser A. 1957;120(3):253-290.

23. Charnes A, Cooper WW, Rhodes E. Measuring the efficiency of decision making units. Eur J Oper Res. 1978;2(6):429-444. doi:10.1016/0377-2217(78)90138-8

24. Ray SC. Data Envelopment Analysis Theory and Techniques for Economics and Operations Research. Cambridge University Press; 2004.

25. Ramanathan R. An Introduction to Data Envelopment Analysis A Tool for Performance Measurement. (Publications S, ed.).; 2003.

26. Charnes A, Cooper WW, Lewin AY, Seiford LM. Data Envelopment Analysis: Theory, Methodology, and Application. Springer Science+Business Media; 1994.

27. Cooper WW, Seiford LM, Tone K. Introduction to Data Envelopment Analysis and Its Uses With DEA-Solver Software and References. Springer Science+Business Media; 2006.

28. Emrouznejad A, Cabanda E. Managing Service Productivity Using Data Envelopment Analysis. In: Emrouznejad A, Cabanda E, eds. Managing Service Productivity Using Frontier Efficiency Methodologies and Multicriteria Decision Making for Improving Service Performance. ; 2014:1-19.

29. Zhu J. Quantitative Models for Performance Evaluation and Benchmarking. Vol 1. Springer Science+Business Media; 2009.

30. Yeşilaydın G. Health Efficiency Measurement in Turkey By Using Data Envelopment Analysis: A Systematic Review. Ankara Săgllk Bilim Derg. 2017;6(123):49-69. doi:10.1501/asbd_0000000062

31. Ertugay N, Tüzüner Z, Bal H. Health Efficiency Measurement In Turkey By Using Data Envelopment Analysis. Conf Proc Sci Technol. 2019;2(1):1-8.

32. Sülkü SN. The impacts of health care reforms on the efficiency of the Turkish public hospitals: Provincial markets. Eur $J$ Public Health. 2012;22(5):634-638.

33. Keskin Hİ. Türkiye'de Sağlıkta Dönüşüm Programı ve Kamu Hastanelerinin Etkinliği. Akdeniz Üniversitesi İktisadi ve İdari Bilim Fakültesi Derg. 2018;(38):124-150. doi:10.25294/auiibfd.492741

34. Golany B, Roll Y. An application procedure of DEA. Omega. 1989;17(3):237-250.

35. Müdürlüğü TCSBSBSG. Sağllk Bakanlığl 2018 Sağlı İstatistikleri Yıllı̆̆l.; 2019.

36. Avkiran NK. Applications of Data Envelopment Analysis in the Service Sector. In: Cooper WW, Seiford LM, Zhou J, eds. Handbook on Data Envelopment Analysis. 2.Edt. Springer Science+Business Media; 2011

37. The R Project for Statistical Computing. Published 2020. Accessed March 14, 2020. https://www.r-project.org

38. Simm J, Besstremyannaya G. Robust Data Envelopment Analysis (DEA) for R. Published online 2020

39. Soylu N. Entelektüel Sermaye Etkinliğinin Veri Zarflama Analizi ile Değerlendirilmesi: BİST Teknoloji Şirketlerine Yönelik Bir Araştırma. Muhasebe ve Finans Derg. 
İBBS-1 bölgelerinin sağllk hizmeti sunum etkinliği.

Özdemir A.

2020;673738(85):269-286. doi:10.25095/mufad.673738

40. Emrouznejad A. Reference set. Published 2020. Accessed March 14, 2020. https://deazone.com/en/reference-set

41. Thanassoulis E. Introduction to the Theory and Application of Data Envelopment Analysis. Springer Science+Business Media New; 2001. 